\title{
Plasma acetate, gluconate and interleukin- 6 profiles during and after cardiopulmonary bypass: a comparison of Plasma-Lyte 148 with a bicarbonate-balanced solution
}

\author{
Paul G Davies ${ }^{1}$, Balasubramanian Venkatesh ${ }^{2 *}$, Thomas J Morgan ${ }^{3}$, Jeffrey J Presneill ${ }^{3}$, Peter S Kruger ${ }^{2}$,
} Bronwyn J Thomas ${ }^{1}$, Michael S Roberts ${ }^{4}$, Julie Mundy ${ }^{5}$

\begin{abstract}
Introduction: As even small concentrations of acetate in the plasma result in pro-inflammatory and cardiotoxic effects, it has been removed from renal replacement fluids. However, Plasma-Lyte 148 (Plasma-Lyte), an electrolyte replacement solution containing acetate plus gluconate is a common circuit prime for cardio-pulmonary bypass (CPB). No published data exist on the peak plasma acetate and gluconate concentrations resulting from the use of Plasma-Lyte 148 during CPB.

Methods: Thirty adult patients were systematically allocated 1:1 to CPB prime with either bicarbonate-balanced fluid (24 mmol/L bicarbonate) or Plasma-Lyte 148. Arterial blood acetate, gluconate and interleukin-6 (IL-6) levels were measured immediately before CPB (T1), three minutes after CPB commencement (T2), immediately before CPB separation (T3), and four hours post separation (T4).

Results: Acetate concentrations (normal 0.04 to $0.07 \mathrm{mmol} / \mathrm{L}$ ) became markedly elevated at T2, where the PlasmaLyte group (median 3.69, range (2.46 to 8.55$)$ ) exceeded the bicarbonate group (0.16 (0.02 to 3.49), $P<0.0005)$. At T3, levels had declined but the differential pattern remained apparent (Plasma-Lyte 0.35 (0.00 to 1.84) versus bicarbonate $0.17(0.00$ to 0.81$)$ ). Normal circulating acetate concentrations were not restored until T4. Similar gluconate concentration profiles and inter-group differences were seen, with a slower T3 decay. IL-6 increased across CPB, peaking at T4, with no clear difference between groups.

Conclusions: Use of acetate containing prime solutions result in supraphysiological plasma concentrations of acetate. The use of acetate-free prime fluid in CPB significantly reduced but did not eliminate large acetate surges in cardiac surgical patients. Complete elimination of acetate surges would require the use of acetate free bolus fluids and cardioplegia solutions.
\end{abstract}

Trial registration: Australia and New Zealand Clinical Trials Register (ANZCTR): ACTRN12610000267055

\section{Introduction}

Open heart surgery utilizing cardio-pulmonary bypass (CPB) is the most common method of cardiac surgery worldwide [1]. A potential complication [2] of CPB is metabolic acidosis, which is influenced by the $\mathrm{CPB}$ circuit priming fluid $[3,4]$. Attempts to prevent metabolic

\footnotetext{
*Correspondence: bala_venkatesh@health.qld.gov.au

${ }^{2}$ Intensive Care Unit, Princess Alexandra and Wesley Hospitals, University of

Queensland, Ipswich Road, Woolloongabba, QLD 4102, Australia

Full list of author information is available at the end of the article
}

acidosis have entailed alterations to circuit prime fluids, including partial replacement of chloride by rapidly metabolised anions such as L-lactate [5,6], acetate and gluconate [3,7], or else by bicarbonate [8]. Plasma-Lyte 148 (Baxter, Toongabbie, NSW, Australia) is a crystalloid CPB prime fluid in common use in Australia and New Zealand (personal communication, Andrew McLaren, Baxter, Australia) in about $7 \%$ of surveyed units in the UK [9] and in some units in North America [10]. One litre of Plasma-Lyte 148 contains $27 \mathrm{mmol}$ acetate
() Biomed Central

(c) 2011 Davies et al.; licensee BioMed Central Ltd. This is an open access article distributed under the terms of the Creative Commons Attribution License (http://creativecommons.org/licenses/by/2.0), which permits unrestricted use, distribution, and reproduction in any medium, provided the original work is properly cited 
and $23 \mathrm{mmol}$ gluconate. In a recent Phase II evaluation of Plasma-Lyte 148 versus a bicarbonate balanced prime, CPB commencing with Plasma-Lyte 148 prime was associated with an immediate surge in unmeasured anions of $>10 \mathrm{mEq} / \mathrm{L}$, with residual elevations still present just prior to CPB cessation [8]. Liskaser and colleagues have reported a similar phenomenon [3]. In both studies the unmeasured anions were considered to be acetate and gluconate; however, neither study measured individual concentrations of either anion at any time point.

Acetate surges in the vasculature may not be benign. For example, in renal replacement therapy, the proinflammatory, vasodilatory, myocardial depressant and hypoxaemia promoting properties of acetate [11-17] led to its removal from contemporary renal replacement fluids. Nevertheless, acetate remains an integral component of commonly used CPB pump prime solutions. Little is known of the acetate concentration profile and consequent physiological impact during cardiac surgery incorporating exposure to acetate-based fluid. The situation concerning gluconate is equally unclear, despite its widespread use.

In this context, we measured concentrations of acetate and gluconate before, during and after $\mathrm{CPB}$ primed with either Plasma-Lyte 148 or an alternative bicarbonatebalanced crystalloid preparation. We also collected preliminary data on plasma IL-6 concentrations as a marker of the systemic inflammatory response accompanying $\mathrm{CPB}$.

\section{Materials and methods}

The protocol was approved by the Human Research Ethics Committee of the Princess Alexandra Hospital and written informed consent was obtained from the patients prior to enrolment (Australian New Zealand Clinical Trials Registry number ACTRN12610000267055).

Patients scheduled for elective cardiac surgery were eligible for enrolment. Exclusion criteria were an abnormal pre-operative venous plasma bicarbonate concentration $(<22 \mathrm{mmol} / \mathrm{L}$ or $>27 \mathrm{mmol} / \mathrm{L})$, hypercapneic respiratory failure, an elevated plasma creatinine concentration ( $>120 \mathrm{micromol} / \mathrm{L}$ ), diabetes mellitus or chronic liver disease.

Patients were assigned systematically to Plasma-Lyte 148 or bicarbonate fluid according to the identity of the available whole-body perfusionist. In the absence of investigator PGD as perfusionist, patients received cardiopulmonary circuit prime as normal with $2 \mathrm{~L}$ of Plasma-Lyte 148. In the presence of investigator PD as perfusionist the $\mathrm{CPB}$ circuit was primed with $2 \mathrm{~L}$ of bicarbonate-balanced fluid made up in the pump immediately prior to priming the circuit by sequential addition of $0.9 \%$ saline $1,130 \mathrm{~mL}, 0.45 \%$ saline $822 \mathrm{~mL}$ (Baxter
Table 1 Composition of cardiopulmonary bypass circuit priming fluids and cardioplegia solution

\begin{tabular}{cccc}
\hline & Plasma-Lyte $\mathbf{1 4 8}$ & Bicarbonate-balanced & Cardioplegia \\
\hline $\mathrm{Na}^{+}$ & 140 & 140 & 140 \\
$\mathrm{Cl}^{-}$ & 98 & 116 & 256 \\
$\mathrm{~K}^{+}$ & 5 & 0 & 83 \\
$\mathrm{Mg}^{2+}$ & 3 & 24 & 80 \\
$\mathrm{HCO}_{3}{ }^{-}$ & & & \\
Acetate & 27 & & 28 \\
Gluconate & 23 & & 24
\end{tabular}

All concentrations in $\mathrm{mmol} / \mathrm{L}$.

Healthcare, Toongabbie, NSW, Australia) and 8.4\% sodium bicarbonate $48 \mathrm{~mL}$ (Astra Pharmaceuticals, Sydney, NSW, Australia). The electrolyte compositions of bicarbonatebalanced fluid and Plasma-Lyte 148, along with the cardioplegia solution employed, are set out in Table 1.

The CPB circuit incorporated a membrane oxygenator (Dideco Avante, Cellplex, Sorin, Mirondola, Italy) and heart lung machine (Jostra HL 20, Maquet Critical Care $\mathrm{AB}$, Solna, Sweden). The standard pump rate was $2.4 \mathrm{~L} /$ minute $/ \mathrm{m}^{2}$ and the target temperature ranged from $32^{\circ} \mathrm{C}$ to $35^{\circ} \mathrm{C}$. Arterial blood was sampled at four time points:

$\mathrm{T} 1$, immediately before commencing $\mathrm{CPB}$; $\mathrm{T} 2$, two minutes after commencement of $\mathrm{CPB}$, prior to placement of the aortic cross-clamp; T3, on rewarming, just prior to separation from CPB; T4, four hours after separation from CPB.

Measurements at each time point included plasma acetate, gluconate and IL- 6 concentrations. Acid-base data were also collected, and are the subject of a separate report. No fluids apart from the patient's allocated prime (Plasma-Lyte 148 or bicarbonate-balanced) were infused in the interval between T1 and T2. Between T2 and T3, cardioplegia was administered. In accord with standard clinical practice at the research centre, an additional Plasma-Lyte 148 boluses were administered to any patient regardless of experimental group if volume supplementation was required.

\section{Acetate and gluconate assay}

Plasma acetate and gluconate concentrations were measured by commercially available kits (Megazyme, Minto, NSW, Australia). Acetate determination is based on the formation of NADH which is measured by the increase in absorbance at $340 \mathrm{~nm}$. Gluconate determination is based on the amount of NADPH formed in the reaction which is stoichiometric with the amount of D-gluconic acid and measured by the increase in absorbance at $340 \mathrm{~nm}$.

\section{IL-6 assay}

Plasma IL-6 was measured using an ELISA technique (Jomar Bioscience Ltd, Kensington, SA). The detection 
antibody was a biotin conjugate antihuman IL-6. Recombinant human IL-6 was used as a standard.

The laboratory scientists performing the acetate, gluconate and the IL- 6 assays were blinded to the group allocation.

\section{Data analysis}

Initial exploratory data analysis involved calculation of summary statistics (non-parametric (Wilcoxon), ( $t$-test) and Fisher exact tests as appropriate) and construction of trajectory plots according to treatment group. Following inspection of these plots, group differences for the change from baseline at selected time points in continuous outcome variables were compared after adjustment for baseline (T1) values using a simple analysis of covariance (ANCOVA) regression model. Natural logarithmic transformations were applied to stabilize the variance of circulating acetate, gluconate and IL-6 levels.

Finally, a population-averaged generalized linear model using a generalized estimating equation (GEE) approach with an unstructured working correlation matrix and robust standard error estimates adjusted for clustering within individual subjects was applied to these longitudinal data to evaluate the overall associations of the vector of (log transformed) acetate, gluconate and IL-6 levels with treatment group across the four time points. Multiple imputation for missing log acetate data was used to support conclusions from the standard generalized linear model.

Statistical analyses were performed using SAS version 9.1 for Windows (SAS Institute, Carey, NC, USA) and Stata version 11.1 (StataCorp. 2010. Stata Statistical Software: Release 11.1. College Station, TX, USA: StataCorp LP).

\section{Results}

The patients' demographic details, type of surgery, $\mathrm{CPB}$ and post-CPB data are summarized in Table 2 according to trial fluid treatment. The Plasma-Lyte 148 and bicarbonate-balanced treatment groups were similar with respect to age and sex, operative type, CPB times, clamp times, volumes of administered cardioplegia, EuroSCORE and Parsonnet indices, incidence of new postoperative atrial fibrillation and frequency of inotrope use. All patients were discharged from the cardiac postoperative unit within 24 hours, and all survived to hospital discharge.

\section{Plasma acetate and gluconate and IL-6}

Arterial blood acetate and gluconate and IL-6 levels, according to time of sample collection, are summarized in Table 3. As well, the time course of each individual subject's acetate and gluconate and IL-6 is illustrated respectively in Figures 1, 2 and 3

\section{Acetate}

Baseline (T1) arterial acetate concentrations were elevated above the normal range $(0.04$ to $0.07 \mathrm{mmol} / \mathrm{L})$ in both groups [18]. These circulating acetate levels became markedly elevated at T2, where, accounting for the $(\log )$ acetate levels at baseline, there was very strong evidence $(P<0.0005)$ of a differential elevation of acetate at T2 compared to T1 in those allocated to Plasma-Lyte 148 compared to bicarbonate fluid. By T3, the substantially higher acetate concentrations in the Plasma-Lyte 148 group were diminished, but relatively normal concentrations were not restored in either group until T4 (Figure 1 and Table 3).

\section{Gluconate}

Overall gluconate levels were also greatest at T2 (Figure 2 and Table 3). Accounting for (log) gluconate levels at baseline, there was also very strong evidence $(P<$ $0.0005)$ of a differentially elevated gluconate level at T2 compared to T1 for patients receiving Plasma-Lyte 148 relative to bicarbonate-balanced fluid. Subsequent circulating gluconate levels declined more slowly than for acetate in patients receiving Plasma-Lyte 148, to again approximate baseline values by $\mathrm{T} 4$ in both groups.

\section{Interleukin-6}

In contrast to acetate and gluconate, overall IL-6 levels increased progressively over time, reaching their maximum values at T4 (Figure 3 and Table 3). Although IL6 levels were higher at T2 in the Plasma-Lyte group $(P<0.05)$, accounting for the $(\log )$ IL-6 levels at baseline, there was no strong evidence $(P=0.12)$ of a difference between the two groups in the change in circulating (log) IL-6 levels from T1 to T4.

\section{Overall population-averaged model}

A marginal population-averaged linear regression model using the GEE approach also returned very strong evidence $(P<0.0005)$ of an independent differential association between administration of Plasma-Lyte 148 versus bicarbonate-balanced fluid as $\mathrm{CPB}$ prime fluid and elevated $(\log )$ circulating acetate levels across time, specifically at $\mathrm{T} 2$.

\section{Discussion}

To our knowledge, this is the first report of serial plasma acetate and gluconate concentrations during and after CBP using Plasma-Lyte 148 prime. We found supra-physiological surges of both anions soon after institution of CBP with Plasma-Lyte 148, with persistent elevations at the end of bypass, particularly of gluconate.

This study documents previously suspected but incompletely characterized effects on serial plasma acetate and gluconate concentrations during and after $\mathrm{CPB}$ using Plasma-Lyte 148 as a CPB circuit priming fluid. It is noteworthy that in both groups, pre-bypass acetate 
Table 2 Patient characteristics according to study fluid

\begin{tabular}{|c|c|c|c|}
\hline & Bicarbonate-balanced & Plasma-Lyte 148 & \\
\hline & $N=15$ & $N_{P}=15$ & $P$ \\
\hline Age, mean (SD), y & $68(8)$ & $68(9)$ & $1.0^{*}$ \\
\hline Sex, male & 12 & 11 & $1.0^{\dagger}$ \\
\hline \multicolumn{4}{|l|}{ Surgical type } \\
\hline CABG & 11 & 12 & $0.7^{\dagger}$ \\
\hline Valve & 4 & 3 & $1.0^{\dagger}$ \\
\hline CPB time, mean (SD), min & $81(31)$ & $80(20)$ & $0.93^{*}$ \\
\hline Clamp time, mean (SD), min & $54(29)$ & $58(20)$ & $0.69^{*}$ \\
\hline Cardioplegia volume, mean (SD), $\mathrm{mL}$ & $325(137)$ & $340(121)$ & $0.74^{*}$ \\
\hline Euro score, median [range] & $3(0$ to 10$)$ & $3(1$ to 7$)$ & $0.9^{\ddagger}$ \\
\hline Parsonnet score, median [range] & 8 (3 to 22$)$ & 8 (3 to 26$)$ & $0.54^{\ddagger}$ \\
\hline New onset atrial fibrillation, $n$ & 4 & 3 & $1.0^{+}$ \\
\hline Inotrope use, $n$ & 2 & 4 & $0.65^{+}$ \\
\hline ICU survival, $n$ & 15 & 15 & $1.0^{+}$ \\
\hline Hospital survival, $n$ & 15 & 15 & $1.0^{\dagger}$ \\
\hline
\end{tabular}

* T test.

† Fisher exact test.

‡ Wilcoxon rank sum test.

CABG, coronary artery bypass grafting.

concentrations were elevated at up to eight times previously reported normal human concentrations of 0.04 to $0.07 \mathrm{mmol} / \mathrm{L}$ [19]. Although increases of both anions were also observed in the group allocated to bicarbonate-balanced CPB prime fluid, these surges were smaller than with Plasma-Lyte 148. There are a number of potential explanations for these findings. First, several patients in both groups were likely to have received Plasma-Lyte 148 before the institution of CPB, as Plasma-Lyte 148 was at the clinical research site the default supplementary fluid for volume loading in either group. It is common practice at the Princess Alexandra Hospital to infuse approximately $1 \mathrm{~L}$ of crystalloid at induction of anaesthesia. Second, all patients received on average over $300 \mathrm{~mL}$ of cardioplegia solution in early $\mathrm{CPB}$ prior to $\mathrm{T} 3$, with this solution containing acetate and gluconate in concentrations similar to Plasma-Lyte 148 (Table 1). Finally, elevated blood acetate concentrations have been reported in patients with type 2 diabetes mellitus [20]. Diabetes was an exclusion criterion for this study, but sub-clinical disease may have been present in some patients.

Although there are no comparative published human reference ranges, it is likely the pre-bypass circulating gluconate concentrations observed in this study were also above normal, related to pre-bypass fluid loading with Plasma-Lyte 148 in numerous patients. Gluconate is known to be eliminated more slowly [21] than acetate. The latter undergoes rapid metabolism at a rate of 300 $\mathrm{mmol} / \mathrm{h}$ in health [22], with a significant extra-hepatic component [13]. This rapid clearance of acetate is preserved in experimental shock states [23], which may in part explain the choice of acetate in preference to L-lactate in 'balanced' resuscitation fluids such as Plasma-Lyte 148. Current data on gluconate metabolism and toxicity in humans are limited, and it is unknown to what extent $\mathrm{CPB}$ alters acetate or gluconate turnover.

Plasma IL- 6 concentrations increased during and in the early hours following $\mathrm{CPB}$ in both groups. The greatest concentrations observed in this study were at four hours following cessation of $\mathrm{CPB}$, consistent with previously reported maxima at three to six hours post CPB $[24,25]$. Unlike acetate and gluconate, IL-6 levels did not show strong evidence of differential changes over time between treatment groups, but the small size of the study precludes assessment of potentially subtle changes.

It remains unresolved whether the demonstrated supra-physiological concentrations of either anion could cause harm. The answer cannot be found in this small non-randomised, incompletely matched cohort study, particularly since substitution of bicarbonate in the circuit prime failed to eliminate exposure to supraphysiological concentrations of acetate and gluconate, for reasons already discussed. However, there is already unequivocal evidence of acetate toxicity in contexts other than CPB. A number of studies have documented hypoxia and hypotension when patients with end stage renal disease were dialysed against solutions containing acetate $[12,13,15]$. There is also evidence of cytokine release, carbohydrate intolerance, disturbances of fatty acid synthesis, reduction of cytosolic redox potential, intracellular accumulation of phosphate, pyrophosphate, phosphorylated intermediates and calcium, and 
Table 3 Untransformed acetate, gluconate and interleukin 6 levels according to time of collection

\begin{tabular}{|c|c|c|c|c|c|c|}
\hline Variable & Fluid & & $\mathrm{T} 1$ & T2 & T3 & T4 \\
\hline \multirow[t]{10}{*}{ Acetate $(\mathrm{mmol} / \mathrm{L})$} & Bicarbonate & mean & 0.17 & 0.49 & 0.24 & 0.03 \\
\hline & & SD & 0.17 & 0.94 & 0.23 & 0.03 \\
\hline & & $\min$ & 0 & 0.02 & 0 & 0 \\
\hline & & median & 0.13 & 0.16 & 0.17 & 0.03 \\
\hline & & $\max$ & 0.64 & 3.49 & 0.81 & 0.08 \\
\hline & P148 & mean & 0.21 & 4.29 & 0.49 & 0.03 \\
\hline & & SD & 0.18 & 1.76 & 0.53 & 0.06 \\
\hline & & $\min$ & 0 & 2.46 & 0 & 0 \\
\hline & & median & 0.18 & 3.69 & 0.35 & 0 \\
\hline & & $\max$ & 0.54 & 8.55 & 1.84 & 0.23 \\
\hline \multirow[t]{10}{*}{ Gluconate $(\mathrm{mmol} / \mathrm{L})$} & Bicarbonate & mean & 0.89 & 1.28 & 2.13 & 0.69 \\
\hline & & SD & 0.54 & 1.50 & 1.05 & 0.38 \\
\hline & & $\min$ & 0.05 & 0.32 & 0.88 & 0.30 \\
\hline & & median & 0.93 & 0.75 & 2.10 & 0.60 \\
\hline & & $\max$ & 1.70 & 6.13 & 3.95 & 1.82 \\
\hline & P148 & mean & 1.20 & 7.44 & 4.31 & 1.33 \\
\hline & & SD & 0.74 & 1.99 & 1.18 & 0.73 \\
\hline & & $\min$ & 0.04 & 4.92 & 2.38 & 0.50 \\
\hline & & median & 1.07 & 6.95 & 3.97 & 1.18 \\
\hline & & $\max$ & 3.18 & 12.1 & 6.51 & 3.42 \\
\hline \multirow[t]{10}{*}{ IL-6 (pg/mL) } & Bicarbonate & mean & 1.75 & 1.88 & 10.3 & 72.5 \\
\hline & & $\mathrm{SD}$ & 0.81 & 0.92 & 13.4 & 49.7 \\
\hline & & $\min$ & 0.51 & 0.74 & 1.67 & 12.1 \\
\hline & & median & 1.69 & 1.55 & 7.14 & 47.9 \\
\hline & & $\max$ & 3.76 & 3.68 & 57.2 & 180 \\
\hline & P148 & mean & 5.99 & 4.72 & 19.2 & 119 \\
\hline & & SD & 12.4 & 8.07 & 21.4 & 74.5 \\
\hline & & $\min$ & 1.06 & 0.89 & 1.84 & 29.0 \\
\hline & & median & 2.65 & 2.7 & 12.5 & 113 \\
\hline & & $\max$ & 50.3 & 33.6 & 62.2 & 309 \\
\hline
\end{tabular}

T1 Immediately before commencing CPB.

T2 Two minutes after commencement of CPB, prior to placement of the aortic cross-clamp.

T3 On rewarming, just prior to separation.

T4 4 hours after separation from CPB.

$\mathrm{SD}$, standard deviation; Min, minimum value; max, maximum value; Bicarbonate, bicarbonate-balanced fluid; P148, Plasma-Lyte 148 fluid.

deposition of intra-mitochondrial calcium and magnesium pyrophosphate [13].

Acetate has also been implicated in direct myocardial toxicity. Patients with chronic renal failure receiving acetate-free haemodiafiltration achieved better stroke volumes, demonstrated a lesser reduction in peripheral resistance and recorded smaller troponin increases than patients receiving conventional acetate-based dialysis [17]. In an isolated perfused rat heart model, exposure of myocardial tissue to acetate concentrations as low as $5 \mathrm{mmol} / \mathrm{L}$ resulted in impaired fatty acid oxidation and decreased ATP turnover [16]. Finally, Plasma-Lyte 148, although promoted as a resuscitation solution, performed poorly in a haemorrhagic shock model. Traverso et al. compared four resuscitation crystalloids [26], and found that Plasma-Lyte148 was associated with a lower survival and a late rise in plasma L-lactate concentrations as compared with normal saline and Ringer's lactate solutions.

Acetate-based haemodialysis in Australia and elsewhere has been abandoned, even in supplementary concentrations although it continues to be an integral component of 'balanced' resuscitation fluids, $\mathrm{CPB}$ priming solutions and total parenteral nutrition. During $\mathrm{CPB}$, adverse effects triggered by acetate exposure would be difficult to detect amongst the vigorous metabolic and host defence responses to surgery [18,27], hypothermia, and non-pulsatile blood flow [1]. Although there is no proven detrimental effect, the concentrations documented in this report suggest a need for further investigations into the safety of acetate containing fluids during $\mathrm{CPB}$. Even more importantly, these investigations should also address the practice of infusing high concentrations of acetate directly into the coronary circulation as part of cardioplegia solution.

Surges in circulating gluconate levels observed in this study were also marked, especially in the Plasma-Lyte 148 group. Unlike acetate, there is no current evidence of clinical or experimental gluconate toxicity, although information is limited. Animal data suggest that at concentrations of 2.4 and $4.8 \mathrm{mmol} / \mathrm{L}$, gluconate may provide protection against post ischemic myocardial dysfunction and oxidative injury [28]. Gluconate has also been incorporated into some enteral and parenteral pharmaceutical preparations. The principal benefit of bicarbonate-balanced fluids demonstrated thus far, apart from avoidance of exogenous anions, is the ability to achieve a well balanced acid-base status across CPB [8]. Also, there is now evidence that added sodium bicarbonate may exert a renal protective effect in CPB [29]. The main difficulty associated with the use of bicarbonate is the need to prevent $\mathrm{CO}_{2}$ loss during preparation and storage [30], and the tendency for precipitation on exposure to small concentrations of calcium and magnesium.

\section{Conclusions}

The use of Plasma-Lyte 148 as a prime fluid resulted in supra-physiological concentrations of acetate and gluconate across $\mathrm{CPB}$. A bicarbonate-balanced pump prime fluid substantially reduced but did not eliminate surges of both anions, due to uncontrolled, clinically-directed 


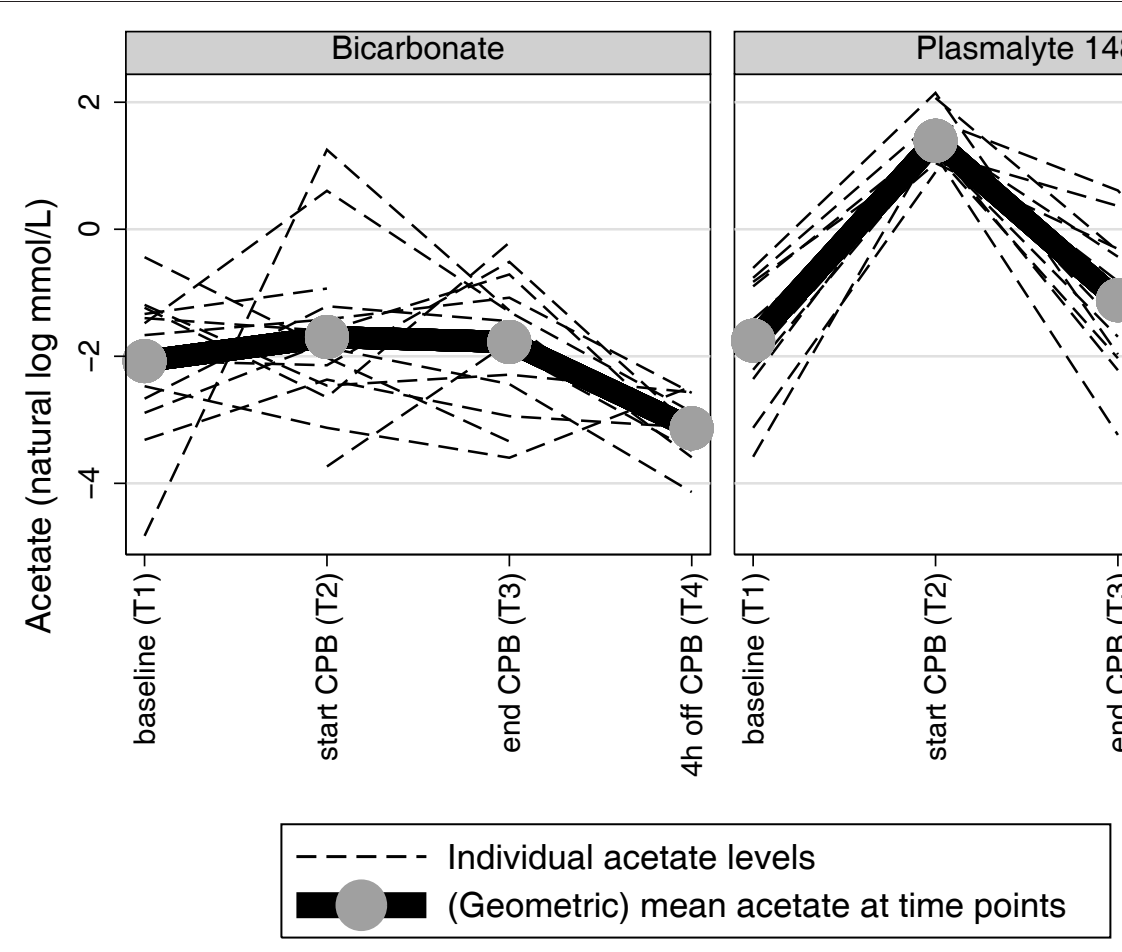

Figure 1 Plasma acetate trajectory plots according to CPB prime, with geometric mean at each time point

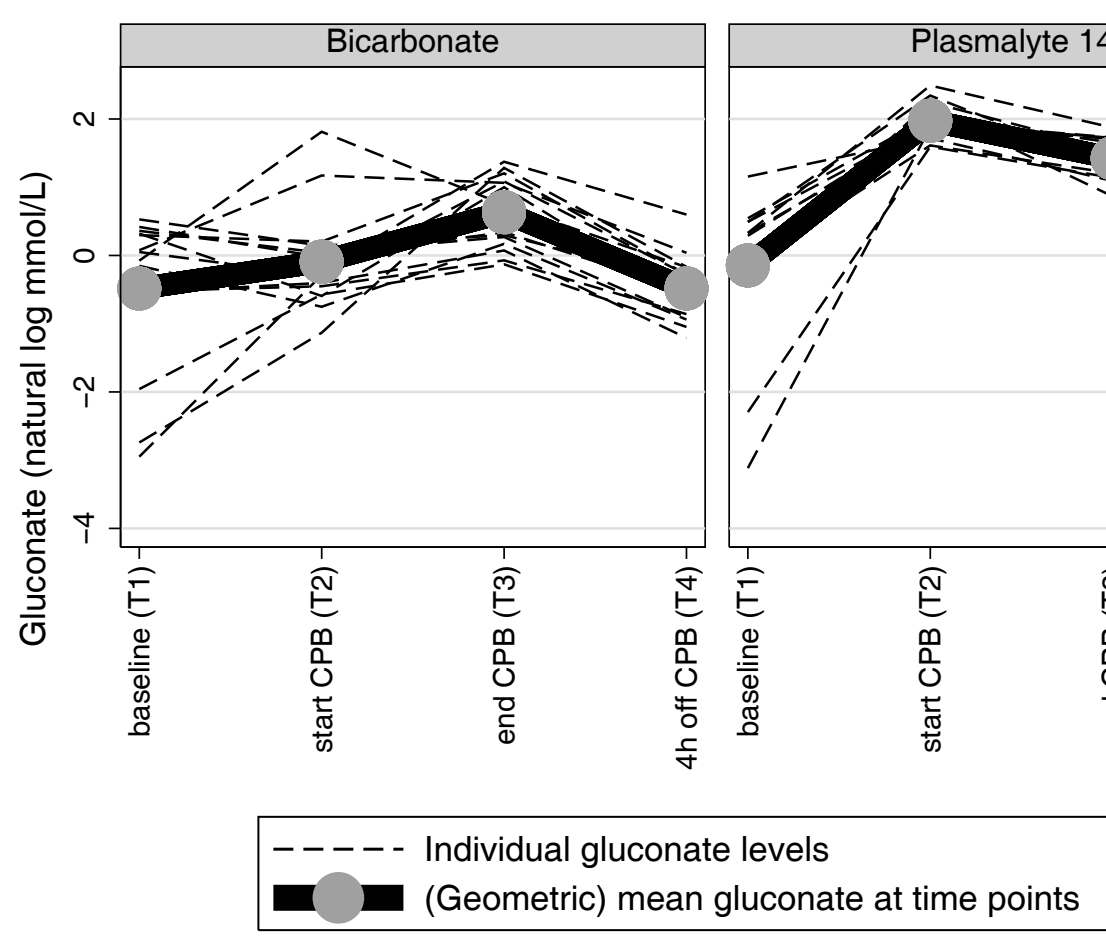

Figure 2 Plasma gluconate trajectory plots according to CPB prime, with geometric mean at each time point. 


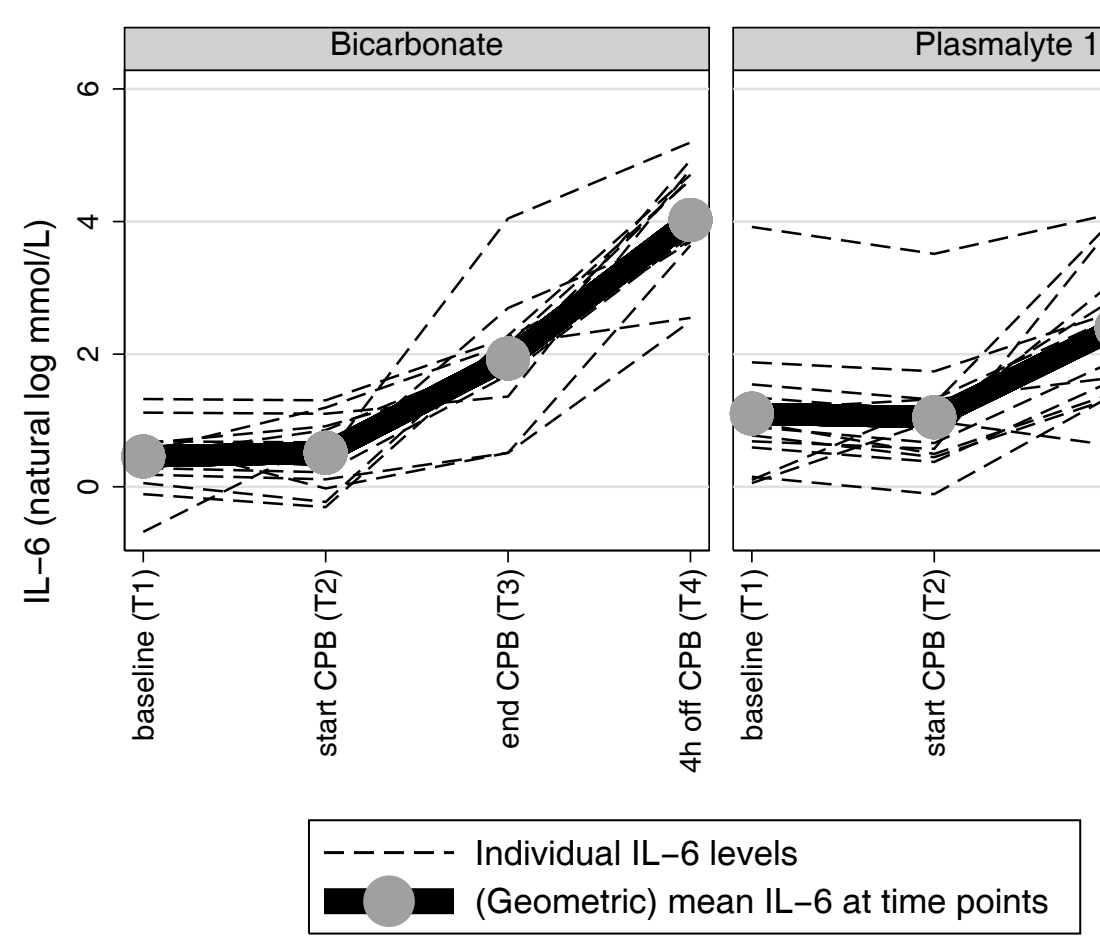

Figure 3 Plasma IL-6 trajectory plots according to CPB prime, with geometric mean at each time point.

administration of fluids containing acetate and gluconate, especially cardioplegia solution. While no clear differences in systemic inflammation were demonstrated, as reflected by circulating IL-6 levels, larger scale studies would be required for more precise assessment of this possibility. Currently, the use of acetate-free prime fluid in $\mathrm{CPB}$ cannot completely eliminate clinical exposure to large acetate surges until acetate is also removed from all other fluids used in $\mathrm{CPB}$, including cardioplegia and bolus fluids. The impact of large plasma concentrations of gluconate also needs further elucidation.

\section{Key messages}

- As even small concentrations of acetate in the plasma result in pro-inflammatory and cardiotoxic effects, it has been removed from renal replacement fluids.

- Acetate containing crystalloids are commonly used as prime solutions in cardiopulmonary bypass.

- This study has identified that supraphysiological concentrations of acetate and gluconate are reached in the plasma of patients undergoing cardiopulmonary bypass with Plasma-Lyte 148 as a prime solution. - The use of acetate-free prime fluid in CPB significantly reduced but did not eliminate large acetate surges in cardiac surgical patients.
- Complete elimination of acetate surges would require the use of acetate free bolus fluids and cardioplegia solutions.

\section{Abbreviations}

CABG: coronary artery bypass grafts; $\mathrm{Cl}^{\text {: }}$ : chloride; CPB: cardiopulmonary bypass; GEE: generalized estimating equations; $\mathrm{HCO}_{3}$ : bicarbonate; IL-6: interleukin-6; $\mathrm{K}^{=}$: potassium; $\mathrm{Na}^{+}$: sodium; P148: plasmalyte 148.

\section{Acknowledgements}

We would like to acknowledge the nursing staff of the operating theaters and the intensive care unit for their assistance with the data collection and Drs. Jeff Grice and Jenny Ordonez for their technical support with the acetate, gluconate and IL-6 assays.

\section{Author details}

'Department of Anaesthesia, Princess Alexandra Hospital, University of Queensland, I Iswich Road, Woolloongabba, QLD 4102, Australia. ${ }^{2}$ Intensive Care Unit, Princess Alexandra and Wesley Hospitals, University of Queensland, I Iswich Road, Woolloongabba, QLD 4102, Australia. ${ }^{3}$ Intensive Care, Mater Misericordiae Hospital, University of Queensland, 550 Stanley Street, South Brisbane, Brisbane, QLD 4101, Australia. ${ }^{4}$ Medicine and Pharmacology, University of Queensland, Chancellors Place, St Lucia, Brisbane QLD 4067, Australia. ${ }^{5}$ Department of Cardiothoracic Surgery, Princess Alexandra Hospital, University of Queensland, Ipswich Road, Woolloongabba, QLD 4102, Australia.

\section{Authors' contributions}

PD was involved in study design and study co-ordination, data analysis and manuscript preparations. BV was involved in overall study design and supervision, data analysis, and manuscript preparation and revision. JM was involved in study design, data analysis and manuscript revision. JP was involved in statistical analysis of data and manuscript revision. PK was 
involved in study design and manuscript preparation and revision. BT was involved in study design and sample collection. MR was involved in biochemical analyses, cytokine analysis and manuscript revision. JM was involved in study design, and manuscript revision. All authors read and approved the final manuscript.

\section{Competing interests}

The authors declare that they have no competing interests.

Received: 30 August 2010 Revised: 18 December 2010 Accepted: 14 January 2011 Published: 14 January 2011

\section{References}

1. Ailawadi G, Zacour RK: Cardiopulmonary bypass/extracorporeal membrane oxygenation/left heart bypass: indications, techniques, and complications. Surg Clin North Am 2009, 89:781-796, vii-viii.

2. Harris EA, Seelye ER, Barratt-Boyes BG: Respiratory and metabolic acidbase changes during cardiopulmonary bypass in man. Br J Anaesth 1970, 42:912-922.

3. Liskaser FJ, Bellomo R, Hayhoe M, Story D, Poustie S, Smith B, Letis A, Bennett $M$ : Role of pump prime in the etiology and pathogenesis of cardiopulmonary bypass-associated acidosis. Anesthesiology 2000, 93:1170-1173.

4. Hayhoe M, Bellomo R, Liu G, McNicol L, Buxton B: The aetiology and pathogenesis of cardiopulmonary bypass-associated metabolic acidosis using polygeline pump prime. Intensive Care Med 1999, 25:680-685.

5. Himpe D, Neels H, De Hert S, Van Cauwelaert P: Adding lactate to the prime solution during hypothermic cardiopulmonary bypass: a quantitative acid-base analysis. Br J Anaesth 2003, 90:440-445.

6. Liskaser F, Story DA, Hayhoe M, Poustie SJ, Bailey MJ, Bellomo R: Effect of pump prime on acidosis, strong-ion-difference and unmeasured ions during cardiopulmonary bypass. Anaesth Intensive Care 2009, 37:767-772.

7. Takkunen O, Salmenpera M, Heinonen J: Comparison of Ringer's acetate and lactate solutions as a prime for cardiopulmonary bypass. Ann Chir Gynaecol 1985, 74:223-227.

8. Morgan TJ, Power G, Venkatesh B, Jones MA: Acid-base effects of a bicarbonate-balanced priming fluid during cardiopulmonary bypass: comparison with Plasma-Lyte 148. A randomised single-blinded study. Anaesth Intensive Care 2008, 36:822-829.

9. Lilley A: The selection of priming fluids for cardiopulmonary bypass in the UK and Ireland. Perfusion 2002, 17:315-319.

10. Sobieski MA, Slaughter MS, Hart DE, Pappas PS, Tatooles AJ: Prospective study on cardiopulmonary bypass prime reduction and its effect on intraoperative blood product and hemoconcentrator use. Perfusion 2005, 20:31-37.

11. Bingel M, Lonnemann G, Koch KM, Dinarello CA, Shaldon S: Enhancement of in-vitro human interleukin-1 production by sodium acetate. Lancet 1987, 1:14-16.

12. Thaha M, Yogiantoro $M$, Soewanto, Pranawa : Correlation between intradialytic hypotension in patients undergoing routine hemodialysis and use of acetate compared in bicarbonate dialysate. Acta Med Indones 2005, 37:145-148.

13. Veech RL, Gitomer WL: The medical and metabolic consequences of administration of sodium acetate. Adv Enzyme Regul 1988, 27:313-343.

14. Schrander-vd Meer AM, ter Wee PM, Kan G, Donker AJ, van Dorp WT: Improved cardiovascular variables during acetate free biofiltration. Clin Nephrol 1999, 51:304-309.

15. Quebbeman EJ, Maierhofer WJ, Piering WF: Mechanisms producing hypoxemia during hemodialysis. Crit Care Med 1984, 12:359-363.

16. Jacob AD, Elkins N, Reiss OK, Chan L, Shapiro Jl: Effects of acetate on energy metabolism and function in the isolated perfused rat heart. Kidney Int 1997, 52:755-760.

17. Selby NM, Fluck RJ, Taal MW, Mclntyre CW: Effects of acetate-free doublechamber hemodiafiltration and standard dialysis on systemic hemodynamics and troponin T levels. ASAIO J 2006, 52:62-69.

18. Kveim M, Bredesen JE: A gas chromatographic method for determination of acetate levels in body fluids. Clin Chim Acta 1979, 92:27-32.

19. Smith RF, Humphreys S, Hockaday TD: The measurement of plasma acetate by a manual or automated technique in diabetic and nondiabetic subjects. Ann Clin Biochem 1986, 23:285-291.
20. Naylor JM, Forsyth GW: The alkalinizing effects of metabolizable bases in the healthy calf. Can J Vet Res 1986, 50:509-516.

21. Richards RH, Vreman HJ, Zager P, Feldman C, Blaschke T, Weiner MW: Acetate metabolism in normal human subjects. Am J Kidney Dis 1982, 2:47-57.

22. Kveim M, Nesbakken R: Utilization of exogenous acetate during canine haemorrhagic shock. Scand J Clin Lab Invest 1979, 39:653-658.

23. Steinberg JB, Kapelanski DP, Olson JD, Weiler JM: Cytokine and complement levels in patients undergoing cardiopulmonary bypass. J Thorac Cardiovasc Surg 1993, 106:1008-1016.

24. Tamayo E, Alvarez FJ, Alonso O, Castrodeza J, Bustamante R, GomezHerreras Jl, Florez S, Rodriguez R: The inflammatory response to colloids and crystalloids used for pump priming during cardiopulmonary bypass. Acta Anaesthesio/ Scand 2008, 52:1204-1212.

25. Traverso LW, Hollenbach SJ, Bolin RB, Langford MJ, DeGuzman LR: Fluid resuscitation after an otherwise fatal hemorrhage: Il. Colloid solutions. $J$ Trauma 1986, 26:176-182.

26. Westaby S: Organ dysfunction after cardiopulmonary bypass. A systemic inflammatory reaction initiated by the extracorporeal circuit. Intensive Care Med 1987, 13:89-95.

27. Jakob SM, Ensinger H, Takala J: Metabolic changes after cardiac surgery. Curr Opin Clin Nutr Metab Care 2001, 4:149-155.

28. Murthi SB, Wise RM, Weglicki WB, Komarov AM, Kramer JH: Mg-gluconate provides superior protection against postischemic dysfunction and oxidative injury compared to Mg-sulfate. Mol Cell Biochem 2003, 245:141-148

29. Haase M, Haase-Fielitz A, Bellomo R, Devarajan P, Story D, Matalanis G, Reade MC, Bagshaw SM, Seevanayagam N, Seevanayagam S, Doolan L, Buxton B, Dragun D: Sodium bicarbonate to prevent increases in serum creatinine after cardiac surgery: a pilot double-blind, randomized controlled trial. Crit Care Med 2009, 37:39-47.

30. Hicks Cl, Gallardo JP, Guillory JK: Stability of sodium bicarbonate injection stored in polypropylene syringes. Am J Hosp Pharm 1972, 29:210-216.

doi:10.1186/cc9966

Cite this article as: Davies et al:: Plasma acetate, gluconate and interleukin 6 profiles during and after cardiopulmonary bypass: a comparison of Plasma-Lyte 148 with a bicarbonate-balanced solution. Critical Care 2011 15:R21.

\section{Submit your next manuscript to BioMed Central and take full advantage of:}

- Convenient online submission

- Thorough peer review

- No space constraints or color figure charges

- Immediate publication on acceptance

- Inclusion in PubMed, CAS, Scopus and Google Scholar

- Research which is freely available for redistribution 